\title{
Scientific Misconduct: A Global Concern
}

\author{
Suvarna Satish Khadilkar ${ }^{1}$
}

Received: 21 August 2018/Accepted: 21 August 2018/Published online: 5 September 2018

(C) Federation of Obstetric \& Gynecological Societies of India 2018

\begin{abstract}
About the Author

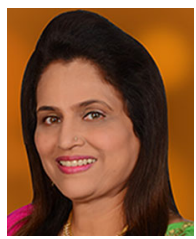

Dr. Mrs. Suvarna Satish Khadilkar is the editor in chief of this journal. She is currently working as Consultant GyneEndocrinologist, Bombay Hospital Institute of Medical Sciences and Medical Research Centre, Mumbai. In the past, she worked as an Associate Professor and Unit Chief at JJ Group of Hospitals and Grant Medical College [GMC], Mumbai, and thereafter in the capacity of the Professor and Head in Department of Obstetrics and Gynecology, Government Medical College, Kolhapur, Maharashtra. She has been an undergraduate and postgraduate teacher and examiner, Mumbai University and Maharashtra University of Health Sciences. Pursuing her interest in endocrinology, she acquired Diploma in Endocrinology from the prestigious University of South Wales, UK, and has been appointed as a recognized teacher in endocrinology in University of South Wales. She is the Treasurer of FOGSI. She has held many prestigious positions like President of Indian Menopause Society, Chairperson of Reproductive Endocrinology Committee of FOGSI, President, Association of Medical Women in India, Mumbai. She is currently the librarian of Mumbai Ob-Gyn Society. She has published six textbooks and more than 70 articles at national and international levels. She is recipient of 30 awards for her research work including the Young Scientist Award.
\end{abstract}

Prof. Suvarna Satish Khadilkar MD DGO FICOG, CIMP, Diploma in Endocrinology (UK) is editor in chief of Journal of Obstetrics and Gynecology of India, and Treasurer, FOGSI; she is Consultant GyneEndocrinologist, Bombay Hospital and Medical Research Centre, Mumbai, Former Professor and Head, Dept of Ob-Gyn, RCSM, Government Medical College, Maharashtra and Asso. Prof. and Unit Chief Grant Medical College and Cama and Albless Hospital, Mumbai.

Suvarna Satish Khadilkar suvarnakhadilkar@yahoo.com; suvarnakhadilkar2@gmail.com

1 Consultant Gyne-Endocrinologist, Bombay Hospital and Medical Research Centre, 12 New Marine Line, Mumbai 400020, India

\begin{abstract}
In today's world, evil appears to be all pervading. Medical publication is no exception. Scientific misconduct in medical writing is slowly becoming a global concern, especially over the last few decades. While the occurrence of such events is certainly rare, every researcher and reader should be aware of this entity. The researcher should ensure that no inadvertent error is construed as misconduct, and should take every effort to guard against it, and the reader should have a critical eye for the same. This article looks into various aspects of scientific misconduct and encourages awareness regarding the same.
\end{abstract}




\section{Introduction}

Do correct. For, He watcheth

Scientific writing continues to be plagued by "tweaks" even in the modern times [1]. The pressures of publishing for a successful medical career seem to be the root cause for this behavior, add to it other influences and incentives!

Scientific integrity in scholarly writing is very important in the medical field as it directly translates into management of our patients. Without high standards of scientific integrity, the scientific community and general public may be adversely impacted as a result of recommendations emerging out of "inferior science." Over last several years, incidents of misconduct are increasingly being reported worldwide. Even apex journals are not spared. It is really sad that false evidence for personal gains continues to muddle science, and hence, each one of us has to introspect and follow the best ethical behavior. As most clinicians do not have a direct access to the "insider information," the impact of inappropriate conduct is probably immense and not accurately measurable. In this context, a statement by the ex-editor of a highly reputed journal is an eye opener to the magnitude of the problem [2].

\section{What is Ethics?}

Ethics is defined as correct behavior dictated internally by one's own moral integrity. Guidelines are the norms for correct behavior laid down but not forced, and law is the correct behavior governed externally or enforced by state. If these are not followed, defaulters may be pulled up for such untoward behavior and even face consequences, blots that no doctor would want in his/her career.

\section{Components of Ethical Research}

Scientific integrity, cordial mentor-trainee relationship, appropriate data acquisition, management, sharing of data and clarity on ownership are the main components of ethical research. Appropriate procedures must be followed for research involving human and animal subjects. Collaborative science formalities, declaration of conflict of interest, commitment of all contributors, appropriate peer review process, good publication practices and responsible authorship are other essential components of ethical research.

Any research activity must be approved by an institutional ethical committee. Informed consent from participants is mandatory. Substandard research or noncompliance may constitute "misconduct."

\section{What is Scientific Misconduct?}

"Research misconduct is defined as fabrication, falsification, or plagiarism in proposing, performing, or reviewing research, or in reporting research results" [3]. Another definition of research misconduct is given as, "as any behavior by a researcher, whether intentional or not, that fails to scrupulously respect high scientific and ethical standards." Various aspects of scientific misconduct are now well recognized and clear definitions are in place [4]. It should be acknowledged that any profession with intelligent individuals can have varying opinions and scientific misconduct does not include honest errors or differences of opinion.

\section{Unethical Practices in Science and Publication}

Sometimes, entire research may be based on research fraud or untrue patient data. Selective or inaccurate publications, plagiarism, or intellectual theft, redundant publication, undeclared conflict of interest, inappropriate authorship, inappropriate acknowledgements, premature public statements are all examples of unethical practices. In the current day context, performing unethical research and publishing without ethical committee permission are indefensible.

\section{Why Do Authors Engage Into Unethical Practices?}

There are several reasons of these practices. One or many may be in action. Even though some may happen out of ignorance, many are done intentionally. In either case, ignorance is unjustifiable in the modern scientific era. Authors aspiring higher positions are under continuous pressure to publish. This pressure may be exerted by their institutes, peers or seniors. Sometimes, overzealous ambition drives individuals down this path. Career prospects and fierce competition may also be a motivation for such actions. Sometimes, lack of publications may lead to loss of incentives such as promotion, or even a possible termination of jobs. In short, they are the victims of "Publish or Perish" system.

Some may not have any knowledge on the ethics or nuances of scholarly writing, so they simply follow what their colleagues have done before. Unfortunately, if the senior colleagues had themselves engaged in unacceptable and unethical practices, it is imperative the juniors may follow suit. It is the bounden moral responsibility of seniors and teachers to lead them on the right path.

Financial incentives from particular sources can also be motivating factors. For example, an author, otherwise 
competent to do good research, may write biased articles to prove the merits of a particular drug manufactured by a particular company, upon financial inducement by the particular drug manufacturer. Some are failures and not capable of doing good work so they engage into misconduct to prove themselves.

\section{At What Stages Can Misconduct Occur?}

Misconduct can be at the level of planning, wherein ideas may be borrowed in a wrong way. It could be at the level of application of permission for conducting the research. Moreover, it could be that research is being done without appropriate permissions. There could be misconduct in the way of collection of data, with deviations from approved protocols. It should be stated here that mere obtaining of permission is not enough, but the protocols approved by the institutional ethics committee should be followed. There could be misconduct in the management of the data. The collection, storing and transmission can lead to many possibilities. Inadequate measures to ensure authenticity of data can itself construed to be misconduct. Data obtained from the subjects should be converted to analysis with good amount of fidelity. Inability to ensure can be viewed upon as misconduct. Hence, it is easy to acknowledge that the ways in which misconduct can occur are multiple, and all researchers must actively guard against it.

\section{Types of Misconduct}

Let us understand various forms of scientific misdeeds and misconducts. Plagiarism is a serious type of offense and will be dealt with separately in the last editorial of the series on medical writing in JOGI. It can happen intentionally or unintentionally. The misconduct can happen at any stage of research. It could happen at the time of planning, or could happen during practical application, and during the process of scientific publication.

- Fabrication means making up data or results and recording or reporting them. It may be noted that even just intent of publishing fabricated data is a misconduct. It is simply reporting something which does not exist.

- Falsification means manipulating research materials, equipment, or processes, or changing or omitting data or results such that the research is not accurately represented in the research record. Example of falsification is manipulation of blood pressure readings in a drug trial evaluating hypertension in pregnancy.
- Obfuscation means omission of critical data or results. Reporting positive outcomes and omitting adverse outcomes are types of obfuscation.

- Plagiarism is the appropriation of another person's ideas, processes, results, or words, without giving appropriate credit. It is an intellectual theft and is a serious offense. This will be dealt with separately in the next issue.

- Unethical research is starting research without obtaining ethical committee permission.

- Conflict of interest can be defined as "a set of conditions in which professional judgment concerning a primary interest (such as patients' welfare or the validity of research) tends to be unduly influenced by a secondary interest (such as financial gain)" [5].

- If authors make active contribution to research without declaring conflict of interest or declaring no conflicts while actually having conflict of interest will amount to misconduct. If author is employee of a company and conducts research on the products of the company without declaring the conflict, the general public may be misguided with the biased study. And patient management will be also misdirected. Authors as well as contributors, editors, reviewers, and publishers should declare conflict of interests.

- Informed consent must be obtained from all participants of the study. Failing to do so amounts to scientific misconduct.

- Irresponsible authorship is the commonest area of allegation of misconduct.

Before understanding what is irresponsible authorship, we need to understand what is "appropriate authorship." International consensus exists on the same. As per International Committee of Medical Journal Editors (ICMJE) Guidelines, authorship credit should be based only on [6]

* Substantial contributions to the conception or design of the work; or the acquisition, analysis, or interpretation of data for the work; and

- Drafting the work or revising it critically for important intellectual content; and

* Final approval of the version to be published; and

* Agreement to be accountable for all aspects of the work in ensuring that questions related to the accuracy or integrity of any part of the work are appropriately investigated and resolved.

The keyword in this definition is the "and". All of the above conditions must be met with. To reiterate, merely being a part of one of the parts of the publication does not justify authorship. 


\section{Inappropriate Authorship}

Simply providing cases, offering authorship to someone not having substantial contribution to the conduct of the research and publication process, omitting authors' names despite their significant contribution, taking credit for the publication but unwillingness to take public responsibility for the data in case of any dispute or litigation, are examples of irresponsible authorship. Most publications insist on a descriptive note on the specific role(s) of each author/contributor to prevent such problems. Some peculiar forms of inappropriate authorship are considered below.

\section{Ghost Writing}

Hiring an author to write an article that is officially credited to another person as author. One typical example is a senior author asking a subordinate to write an article, with credit going only to the senior author, and not the junior. Not writing any part of the article, but paying someone to write it is considered ghost writing.

\section{Guest Authorship}

Intentional inclusion of name of a reputed senior author who has not contributed to the research or publication. This is done to increase the chances of acceptance by journal editors. Offering authorship to close relatives without having any role to play in the making of the paper is the example of guest authorship.

\section{- Acknowledgements}

The individuals who do not meet authorship criteria, but who have assisted the research by their encouragement and advice or by providing space, financial support, reagents, routine analyses, or patient material should be acknowledged in the text. Performance of routine work or duty funding/sponsoring agency, being head of an institute/department, does not qualify for authorship, unless they fulfill the above-mentioned criteria. Hence, if need be they should be only acknowledged.

\section{- Publication bias and misconduct}

* Positive trials are more likely to be submitted and published quickly. Some trials which did not have positive results may never be published [7].

* Suppression - the failure to publish significant findings due to the results being adverse to the interests of the researcher or his/her sponsor(s).

* Publication of deliberately false or misleading research.
* Bare assertions-making entirely unsubstantiated claims and making baseless and unverifiable conclusions entirely unrelated to data.

* Quoting fake references, and/or quote which do not support the argument.

- Premature publication: In the current generation, news travels fast. Exposing a fact in one mass media implies that it can reach the entire world. However, this should not corrode due to scientific processes. It is advisable that dissemination of study results through various media should take place only after publication, or at least simultaneously.

Apart from ICMJE, other institutions have also come up with recommendations and guidelines.

ICMR Guidelines The Indian Council of Medical Research has published an exhaustive article titled "National Ethical Guidelines for Biomedical and Health Research Involving Human Participants." One section of this guideline is titled "Responsible conduct of Research." Under this section, the topics "Reviewing and reporting research," "Responsible authorship and publication" and "Research misconduct and policies for handling misconduct" are covered in detail. It is hereby suggested that everyone be conversant with these guidelines [8].

Committee on Publication Ethics (COPE) In the recent few decades, a substantial spurt in the occurrence of publication misconduct prompted many editors of prominent journals to come together and form an entity named COPE. The motto of COPE states "Promoting integrity in research and its publication." What started off as an experimental initiative, now meets and publishes guidelines regarding publication ethics. Cases (of misconduct) and findings are discussed, and best practices for authors and editors are published. It is now seen as a standard in scientific publishing, and our authors and readers to will benefit by referring to the detailed publications of COPE [9].

Similarly, World Association of Medical Editors (WAME) is another organization which is a forum where editors of many medical journals have come together to frame guidelines regarding standardization of publication practices [10].

To summarize, integrity is the soul of research. Ethical research and sound publication ethics are a necessary continuum in the process of upliftment of medical knowledge. Researchers, authors, editors, reviewers, publishers and sponsors should be aware and fulfill their respective responsibilities. Good ethical research is a step toward scientific evolution which will help us achieve final goal "women's Health." 


\section{References}

1. Deshmukh MA, Dodamani AS, Khairnar MR, et al. Research misconduct: a neglected plague. Indian J Public Health. 2017;61(1):33-6.

2. The Ethical Nag. https://ethicalnag.org/2009/11/09/nejm-editor/. Accessed 18 Aug 2018.

3. Federal Research Misconduct Policy. https://ori.hhs.gov/ federal-research-misconduct-policy. Accessed 18 Aug 2018

4. Smith R. Research misconduct: the poisoning of the well. J R Soc Med. 2006;99(5):232-7.

5. Greco D, Diniz NM. Conflicts of interest in research involving human beings. J Int Bioeth. 2008;19(1-2):143-54.

6. Defining the Role of Authors and Contributors. http://www. icmje.org/recommendations/browse/roles-and-responsibilities/ defining-the-role-of-authors-and-contributors.html. Accessed 18 Aug 2018.

7. Brænd AM, Straand J, Jakobsen RB, et al. Publication and nonpublication of drug trial results: a 10-year cohort of trials in Norwegian general practice. BMJ Open. 2016;6(4):e010535.

8. National Ethical Guidelines for Biomedical and Health Research Involving Human Participants. http://thsti.res.in/pdf/ICMR_ Ethical_Guidelines_2017.pdf. Accessed 18 Aug 2018.

9. Committee On Publication Ethics. https://publicationethics.org/. Accessed 18 Aug 2018.

10. World Association of Medical editors. http://www.wame.org/ index.php. Accessed 18 Aug 2018. 